\title{
A REVISTA NOVA ESCOLA NO PERÍODO DE 2003 A 2010 E A FORMAÇÃo DE PROFESSORES ${ }^{1}$
}

\author{
LA REVISTA NOVA ESCOLA EN EL PERÍODO 2003-2010 Y LA \\ FORMACIÓN DE PROFESORES \\ NOVA ESCOLA MAGAZINE FROM 2003 TO 2010 AND THE TEACHERS \\ TRAINING
}

\author{
Andréia Cristina Fregate Baraldi LABEGALINI ${ }^{2}$ \\ Carlos da Fonseca BRANDÃO ${ }^{3}$
}

RESUMO: A presente pesquisa investigou como a Revista Nova Escola (RNE) retratou e interpretou aspectos da política educacional pública empreendida pelo Governo Luís Inácio Lula da Silva (2003-2010), tanto no nível das suas propostas legislativas, quanto político-pedagógicas, no âmbito da formação de professores. No contexto das suas propostas político-pedagógicas, analisamos como esse periódico trabalhou a formação de professores por meio dos aspectos formação inicial, formação continuada, carreira e práticas de sala de aula. A Revista Nova Escola, para além de suas opiniões, também colabora com a formação continuada dos professores.

PALAVRAS-CHAVE: Política educacional pública. Revista Nova Escola. Propostas político-pedagógicas.

RESUMEN: Se investigó la forma en la Revista Nova Escola (RNE) retrata e interpreta los aspectos de la política de educación pública llevadas a cabo por el gobierno de Luiz Inácio Lula da Silva (2003-2010), tanto en términos de sus propuestas legislativas, la política-educativa en la formación de profesores. En el contexto de sus propuestas políticas y educativas, se analiza cómo funcionaba la formación continua del profesorado a través aspectos de formación inicial, formación continua, de carrera y prácticas en el aula. La Revista Nova Escola, además de sus opiniones, también colabora con la formación continua de los profesores.

PALABRAS CLAVE: Política de la Educación Pública. Revista Nova Escola. propuestas políticas y educativas.

${ }^{1} \mathrm{O}$ texto apresenta resultado de pesquisa desenvolvida no âmbito do Grupo de Pesquisa intitulado Coletivo de Pesquisadores em Políticas Educacionais - COPPE.

2 Doutora em Educação (Unesp/Marília), membro do Grupo de Pesquisa intitulado Coletivo de Pesquisadores em Políticas Educacionais - COPPE; pós-doutoranda em Educação (Unesp/Assis) e docente da Universidade de Marília.

${ }^{3}$ Livre-docente, professor adjunto do Departamento de Educação da UNESP - Assis e do Programa de Pós-graduação em Educação da UNESP - Marília e coordenador do Grupo de Pesquisa intitulado Coletivo de Pesquisadores em Políticas Educacionais - COPPE. 
ABSTRACT: This research investigated how the Revista Nova Escola (RNE) portrayed and interpreted aspects of public education policy undertaken by the government Luiz. Inacio Lula da Silva (2003-2010), both in terms of its legislative proposals, the political-pedagogical within the teacher training. In the context of its political and educational proposals, we analyze how this periodic saw the teacher training through aspects initial training, continuing education, career and classroom practices. The Revista Nova Escola, in addition to their opinions, also collaborates with the continuing education of teachers.

KEY WORDS: Public education policy. Revista Nova Escola. Political and educational proposals.

\section{Introdução}

A Revista Nova Escola (RNE) é uma publicação da Fundação Victor Civita, mantida pela Editora Abril, e existe desde março de 1986. Escolhemos esse periódico para abordar a questão da formação de professores por diferentes razões. A primeira delas é que no Brasil, são raros os periódicos que conseguem se manter ativos por 30 anos, como é o caso da Revista Nova Escola (RNE). A segunda das razões é que esse periódico não é, em sentido estrito, um periódico acadêmico-científico, pois nele não encontramos a publicação de pesquisas acadêmicas e científicas com os rigores teóricometodológicos inerentes às mesmas.

A terceira razão é que podemos definir, grosso modo, esse periódico como sendo um periódico "quase-comercial", no sentido de que, apesar de vender publicidade e de assinaturas, o mesmo é fortemente financiado, pela Fundação Victor Civita e por sua mantenedora, a Editora Abril. Apesar de não estarmos preocupados com os dados numéricos desse financiamento, podemos dizer que a RNE não depende, significativamente, da venda de publicidade e de assinaturas pelo fato do valor de uma assinatura ser muito pequeno e porque a RNE é distribuída gratuitamente no sistema estadual público paulista e em outros Estados e Municípios.

A nossa quarta razão por termos escolhido a RNE para analisarmos como ela interpreta, e divulga a questão da formação de professores em um dado período histórico (2003-2010) é exatamente em função dessa sua última característica, quer seja, a sua distribuição gratuita em muitas escolas públicas do país. Assim, podemos dizer que esse periódico "circula" nas escolas públicas brasileiras e, partiremos do pressuposto de que muitos professores dessas escolas, de uma forma ou de outra, têm na RNE uma fonte de informação e de apoio pedagógico. 
Assim que adentramos à análise da RNE, a primeira coisa que percebemos é a multiplicidade de seções (próprias de um periódico) e a diversidade de temáticas. Não nos pautamos pela estrutura da revista e de suas seções, mas sim pelas temáticas que as diferentes seções abordam e, dentro de tantas temáticas, escolhemos discutir a questão da formação de professores. Já a escolha desse determinado período histórico (20032010) para a nossa análise foi feita de maneira relativamente "casual", mas de maneira alguma politicamente neutra. Dizemos "casual" porque no momento que pensamos em iniciar um novo projeto de pesquisa foi o momento em que acabava de se encerrar o Governo Luís Inácio Lula da Silva, presidente esse que obteve, ao final de seus dois mandatos (2003-2006 e 2007-2010) os maiores índices de aprovação popular da história republicana do Brasil.

Ao mesmo tempo, nossa escolha não é de maneira nenhuma neutra. Em primeiro lugar porque não existe escolha neutra. Em segundo lugar porque a Editora Abril, mantenedora da Fundação Victor Civita, responsável esta pela publicação da Revista Nova Escola (RNE) também é responsável por outras publicações com viés deliberadamente crítico a qualquer governo ou proposta que não esteja no campo ideológico conservador. O Governo de Luís Inácio Lula da Silva (2003-2010) pode não ter sido, no geral e especificamente no campo educacional, o governo dos sonhos dos progressistas mas, com toda certeza, não foi um governo que poderíamos chamar de conservador.

Essas constatações, entre tantas outras, nos levaram à indagação de querer saber como uma revista distribuída em muitas escolas públicas do Brasil, mantida e financiada por um grande grupo de mídia conservador, "olhou", no sentido de interpretar, as diferentes propostas sobre a formação de professores surgidas no período analisado (2003-2010).

\section{A formação de professores presente nos artigos}

A formação de professores nos artigos encontrados apresentou-se em diferentes colunas (seções da revista), no entanto, sem concentrar-se em nenhuma delas. Após uma primeira análise dos artigos de acordo com as seções da revista onde foram publicados, reunimos aqueles que tratavam dos mesmos assuntos e construímos quatro categorias: formação inicial, formação continuada, carreira e práticas de sala de aula. 
A categoria Formação inicial englobou artigos publicados nas seguintes seções da revista: Fique por dentro (1 artigo); Políticas públicas (1 artigo); Formação InicialLicenciaturas (1 artigo); Em dia - Notas sobre Educação - Formação (1 artigo); Em dia - Notas sobre Educação - Pesquisa (1 artigo); Em dia - Notas sobre Educação - Ensino Fundamental (1 artigo); Capa - Formação (1 artigo); Capa - Formação Inicial (1 artigo); Pense Nisso (2 artigo); Fala, Mestre! (2 artigos) e em artigo que não estava em nenhuma seção específica.

A categoria Formação continuada esteve presente nas seguintes seções da revista: Capa - Formação Continuada (1 artigo); Encarte - Capacitação (1 artigo); Profissão Professor (1 artigo); Educação em foco (1 artigo); Em dia - Notas sobre Educação - Formação (1 artigo); Pense Nisso (1 artigo).

Já a categoria Carreira apresentou artigos publicados nas seguintes seções da revista: Mercado e Formação (1 artigo); Em dia - Notas sobre Educação - Formação (1 artigo); Matéria de capa (1 artigo); Políticas públicas - Carreira (3 artigos); Pense Nisso (1 artigo); Capa - Formação no Mundo (1 artigo); Fala, Mestre! (1 artigo); Caro Educador (1 artigo) e dois artigos que não estavam em nenhuma seção específica da revista.

Por fim, na categoria Práticas de sala de aula foi encontrado um artigo que não estava em nenhuma seção específica da revista além de: Mural (1 artigo); Em dia Notas sobre Educação (1 artigo); Fala, Mestre! (1 artigo); Capa - Carreira (1 artigo).

A seguir, passaremos a analisar o que consideramos que podemos deduzir sobre o que a Revista Nova Escola expressou, no período analisado (2003 a 2010) a respeito da questão da formação de professores por meio do que foi publicado em cada uma das quatro categorias acima explicitadas.

\section{Formação inicial}

Dentre os treze textos selecionados e organizados cronologicamente, o primeiro (FERRARI; FUSCO, 2004) trata do final dos cursos de magistério em nível médio, impulsionado pela Lei 9394/96. Apesar do artigo 62 da LDB admitir a formação oferecida em nível médio como sendo a mínima para o exercício do magistério na educação infantil e nas quatro primeiras séries do ensino fundamental, de acordo com a Lei no 10 172/2001, até 2011 70\% deverão possuir formação específica de nível superior. 
Destaca-se a impossibilidade das universidades públicas atenderem totalmente a demanda, o que torna a formação de nível médio ainda mais importante. Para reforçar, apresenta também a qualidade "[...] nem sempre satisfatória das universidades privadas, que acabam sendo a alternativa possível para a aprendizagem de um grande número de profissionais da educação" (FERRARI; FUSCO, 2004, p.34). Mas também há a sugestão de Guiomar Namo de Mello a respeito de articular os cursos normais de nível médio com os cursos superiores: o aluno que já concluiu o curso normal e ingressa na faculdade poderia exercer a função de auxiliar de classe, como uma espécie de residência.

Ainda no mesmo ano a revista publicou uma entrevista com o sociólogo suíço Philippe Perrenoud, cujas ideias sobre práticas pedagógicas influenciaram as reformas educacionais no Brasil (FERRARI, 2004. p. 20-22). Especificamente a respeito dos professores, Perrenoud afirma que "A formação exige não só que eles dominem o saber mas também que saibam fazer a transposição desse saber" (FERRARI, 2004, p. 22). Ele afirma também que

[...] é necessário rever a formação inicial dos docentes para dar mais ênfase às competências de transposição e de gerenciamento do saber. A habilidade se desenvolve ao longo da vida, à medida que surgem os obstáculos. [...] Quanto mais qualificado for um profissional, maior deverá ser sua capacidade de enfrentar o imprevisível. (FERRARI, 2004. p. 22).

Em 2006 a revista apresenta um artigo intitulado "Os limites do curso de Pedagogia", destacando que currículos e enfoques tradicionais não oferecem formação nas disciplinas das séries iniciais e tentam abarcar objetivos amplos demais para serem atendidos (DURHAM, 2006, p. 78). Ao mesmo tempo, o artigo afirma que também o nível médio é insuficiente para capacitar os professores das séries iniciais e que a revalorização da carreira passa pela formação que assegure o domínio das áreas de conhecimento com as quais o profissional lida. $\mathrm{O}$ artigo defende que a Pedagogia ficou sem identidade na medida que se atribui a ela um triplo objetivo: 
[...] formar pesquisadores e pessoal qualificado para refletir sobre o sistema educacional, preparar professores aptos a lecionar as matérias pedagógicas que faziam parte do currículo das Escolas Normais e capacitar o pessoal especializado para a gestão do sistema escolar, como administradores, orientadores ou supervisores escolares. (DURHAM, 2006, p.78).

No contexto do artigo, a autora deixa claro que, em sua opinião, não é possível que um curso de pedagogia consiga englobar todos esses conteúdos.

A revista traz em 2007 um artigo destacando que o novo Plano Nacional para a Educação não pode esquecer que, para garantir um ensino de qualidade, precisamos formar professores com muito preparo conceitual e técnico (MENEZES, 2007a, p. 18). Novamente a formação de professores ganha destaque, pois o autor afirma que só o bom professor salva. Há a preocupação com os cursos de Pedagogia que sobrecarregam a visão sistêmica e administrativa, com prejuízo da formação para a sala de aula. "[...] é preciso evitar que uma pedagogia do discurso predomine sobre a arte de ensinar ou que a preleção abstrata tome espaço da vivência didática". Sugere-se uma "residência pedagógica" e como ideal uma formação articulada com redes municipais e estaduais, com cooperação mútua: as universidades fariam o aperfeiçoamento permanente em serviço e as escolas garantiriam as atividades práticas da formação inicial, pois, “[...] sem bons professores não há boas escolas [...]”.

No mesmo ano (DIDONÊ, 2007, p. 60-64), volta a já citada ideia de residência pedagógica, agora proposta em um projeto de lei em trâmite no Senado, o objetivo é oferecer aos novos professores um contato mais efetivo com a realidade escolar logo após a graduação, para a melhoria da formação docente e prevendo que as universidades passarão a cobrar mais dos estudantes, tornando os estudos "mais puxados". A residência elevaria as horas de estágio: de 300 para 800.

Fica clara, no artigo, a valorização da formação inicial atrelada à formação contínua, buscando construir um profissional autônomo, que reflete, toma decisões e divide tarefas. Para tanto, o autor afirma que "[...] o docente precisa de mais tempo de estudo" (DIDONÊ, 2007, p. 64).

Também em 2007 foi publicado um artigo com o passo a passo para garantir que os sistemas de Ensino Básico e Superior atuem de forma cooperativa para dar melhor Educação para todos (MENEZES, 2007b, p. 22). O autor esclarece que o texto foi produzido para "explicar melhor" o seu plano de formação de professores realizado em 
parceria com as escolas onde a prática acontece. O plano consiste em seis etapas: diagnóstico, desafio, conspiração, tutores e "residentes", números e, futuro.

Em 2008 a revista trata de uma pesquisa encomendada à Fundação Carlos Chagas, que analisou setenta e um currículos de cursos de Pedagogia oferecidos por instituições públicas e particulares de todo o Brasil, apontando um descompasso "preocupante" entre o que as faculdades oferecem aos futuros professores e a realidade encontrada por eles nas escolas (GURGEL, 2008a, p. 48 - 49).

A revista novamente contempla o currículo dos cursos de Pedagogia, trazendo resultados de uma pesquisa da Fundação Carlos Chagas para a Nova Escola, mostrando que o curso não contempla o "quê" e o "como" ensinar e nem prepara para a realidade escolar (GURGEL, 2008b. p. 50 - 53). O curso de Pedagogia “[...] deveria garantir a competência de quem leciona na Educação Infantil e nas primeiras séries do Ensino Fundamental, forma profissionais despreparados para planejar, ensinar e avaliar. O resultado é a péssima qualidade da educação no país." (GURGEL, 2008b. p. 50). A pesquisa mostrou um currículo fragmentado: foram analisados 71 currículos e identificadas 1968 disciplinas diferentes sem correspondente em nenhuma outra instituição. Para finalizar o artigo apresenta que o curso de Pedagogia eficiente valoriza as didáticas específicas, promove estágios supervisionados, ensina a planejar, avaliar e registrar e também contempla os segmentos do ensino.

No mesma revista do mês de outubro de 2008, foi publicada uma entrevista com o então Ministro da Educação Fernando Haddad (PELLEGRINI; GROSSI, 2008, p. 3236) intitulada A formação docente é prioridade para o Ministério. Trata-se da formação de professores para o Ensino Fundamental, que, em 2009 receberá, segundo o artigo, dez milhões a mais do que em 2008. “[...] os cursos de Pedagogia e o Normal Superior foram considerados - ao lado dos de Medicina e Direito - prioritários numa lista de avaliações nacionais de faculdades e universidades" (PELLEGRINI; GROSSI, 2008, p. 32). O artigo traz a criação do Sistema Nacional de Formação do Magistério, que contará com a articulação entre dirigentes municipais, estaduais e instituições de Ensino Superior. Novamente o curso de Pedagogia sofre críticas:

[...] justamente porque o curso de Pedagogia não está preparado para formar professores, esse é o desafio do Sistema Nacional de Formação do Magistério [...]. É preciso também que as faculdades adaptem os currículos dos cursos de Pedagogia à realidade da sala de aula [...]. O fato é que é preciso incluir as 
competências básicas sobre o dia-a-dia da sala de aula, que sempre foram uma característica do curso Normal. (PELLEGRINI; GROSSI, 2008, p. 34).

Além dos aspectos já destacados, o ministro também ressaltou que a formação do Magistério deve ser feita em regime de colaboração entre União, estados e municípios.

Neste mesmo ano (2008) a revista também abordou a formação de professores nas licenciaturas de Letras, Matemática e Ciências Biológicas, mostrando que os docentes formados têm pouco contato com disciplinas voltadas para como ensinar (LEVORATTI, 2008, p. 76-79). Novamente a revista utilizou pesquisa da Fundação Carlos Chagas para a revista Nova Escola, onde foi constatado que dedica-se mais tempo à aprendizagem de conhecimentos da área do que de ensino de didáticas, o que mostra que há pouca valorização para a preparação para a atuação docente.

Em 2009 a revista aponta que já houve um crescimento do número de professores com curso superior, porém, os especialistas estão fora de lugar (SANTOMAURO, 2009, p. 46). Foram utilizados dados do Estudo Exploratório sobre o Professor Brasileiro, trata-se de levantamento realizado no Censo 2007 pelo Instituto Nacional de Estudos e Pesquisas (INEP). Constatou-se que 73,4\% dos professores do $6^{\circ}$ ao $9^{\circ}$ ano já têm formação superior e licenciatura, "Porém, apesar de lecionarem uma disciplina específica, a maioria não tem formação ligada ao que ensina" (SANTOMAURO, 2009, p. 46).

Ainda em 2009, os cursos de Pedagogia voltam à discussão: a revista aponta que poucos cursos de Pedagogia são excelentes (VICHESSI, 2009, p. 44); o artigo refere-se aos cursos avaliados pelo ENADE de 2005 e que não melhoraram seus conceitos no ENADE de 2008: 10 cursos passaram 3 anos sob supervisão do MEC e foram fechados e muitos outros avaliados com conceitos 1 ou 2 continuam em atividade. Conclui-se que “[...] no fim deste e dos próximos anos, mais educadores vão concluir uma formação precária e adentrar as escolas do país sem condições de ensinar os alunos com competência" (VICHESSI, 2009, p. 44).

Novamente utilizando dados do Instituto Nacional de Estudos e Pesquisas (INEP), em 2010 a revista publicou um artigo informando que o número de não formados diminui (NICOLIELO, 2010, p. 56). Constatou-se que 24\% dos professores das séries finais do Ensino Fundamental não têm a formação adequada para lecionar nesse nível, que seria, conforme a LDB, nível superior com licenciatura. São eles: 
professores sem nível superior ou formados em outras áreas, como a de engenharia ou saúde. Apesar de haver a diminuição do número de docentes sem a formação mínima, isso não está ocorrendo na velocidade necessária para que todos estejam formados até 2011.

\section{Formação continuada}

Foram selecionados seis textos que tratam diretamente do tema formação continuada, publicados pela revista Nova Escola no período de 2003 a 2010. Nós os organizamos cronologicamente, sendo que o primeiro (GUIMARÃES, 2003, p. 60-62) trata do Programa de Formação de Professores Alfabetizadores (Profa), criado a pedido do Ministério da Educação (MEC) e cuja idealizadora é a educadora Telma Weisz. O Profa era destinado a professores de Educação Infantil e Ensino Fundamental (inclusive para alfabetizadores de adultos) e fazia acompanhamento constante do trabalho em sala de aula, sendo aprovado por quase noventa mil professores. O texto informa também a respeito da necessidade de formar um grupo na escola para começar a estudar, aliando paciência e persistência.

Ainda em 2003 a revista ressaltou que "A formação continuada não é moda passageira. Reflete o mundo cada vez mais veloz em que vivemos, que se renova a cada instante" (PRADO, 2003, p. 18). Para justificar a necessidade de formação contínua o texto informa que há muita informação, rápida e disponível, além disso, a escola mudou e os alunos também mudaram. Ressalta a importância do professor tematizar com os seus colegas o que acontece na sala de aula, aumentando suas condições de lidar com questões inesperadas.

Em dezembro de 2004 a revista abordou a Rede Nacional de Formação de Professores, em que vinte centros universitários prepararam material para capacitar docentes das redes públicas a partir de 2005 (VEM, 2004). A capacitação era para professores de Educação Infantil e Ensino Fundamental, por meio de cursos presenciais, semipresenciais e a distância. Informa o texto que os organizadores da Rede veem o próprio ambiente de trabalho do professor como sendo o espaço mais fértil para o aprimoramento e, para tanto, serão preparados tutores para orientarem os grupos de estudos que serão agregados por escola, rede ou região. 
O próximo artigo que trata de formação continuada, localizado pelos integrantes do COPPE, data de 2008 (MENEZES, 2008, p. 122). Nele o autor afirma que os professores, que em artigo anterior (publicado na revista de novembro de 2007) já assumiram seu despreparo para atuar em sala de aula, “[...] fizeram cursos ruins e inadequados à realidade, sem supervisão prática das atividades em sala de aula" e, por esse motivo, “[...] precisamos urgentemente oferecer programas de apoio pedagógico e de formação em serviço na própria Educação pública" (MENEZES, 2008, p. 122). Em resumo, há necessidade, na opinião do autor, de rever a formação inicial e a continuada.

Ainda em 2008 foi publicado um artigo informando que nas redes públicas faltam programas realmente preocupados com a continuidade da capacitação docente (MARTINS et al, 2008, p. 54 - 57). Em 2007 cinquenta e dois milhões foram investidos pelo MEC e também houve investimentos realizados pelas secretarias estaduais e municipais de Educação, já que há recursos do Fundeb. Ressalta-se que, [...] em virtude da deficiência de formação inicial dos professores, em muitas dessas ações é necessário abordar temas que já deveriam ter sido aprendidos na universidade" (MARTINS et al, 2008, p. 54); além disso, são oferecidos, a título de formação continuada, cursos de curta duração, palestras e seminários que, não acompanham a evolução do professor e nem mudam a forma como ele trabalha, ferindo o princípio da formação continuada: a realização de um trabalho contínuo. Para reforçar o ponto de vista, o texto informa que "A atividade desenvolvida por coordenadores pedagógicos durante o horário coletivo é a iniciativa que apresenta resultados mais efetivos" (MARTINS et al, 2008, p. 55). Ainda segundo o artigo, a boa formação continuada conjuga uma série de fatores: conhecimento da realidade local, utilização de formadores experientes, valorização do contexto profissional, previsão de estudo contínuo e para todos, ajuda a formar novos quadros e tem foco no conhecimento didático.

Em setembro de 2009 a revista abordou um estudo da Organização para a Cooperação e Desenvolvimento Econômico (OCDE), realizado em vinte e três países (incluindo o Brasil), a respeito do cenário da formação continuada (ESTUDO, 2009, p. 50). Constatou-se que $90 \%$ dos docentes das séries iniciais do segundo ciclo do Ensino Fundamental de vinte e três países estudam para se desenvolverem profissionalmente.

\section{Carreira}


Dentre os doze textos selecionados no âmbito do COPPE, o primeiro a tratar da carreira docente foi publicado em 2007 (GUIMARÃES; FARIA, 2007, p. 26-37). Com o intuito de entender melhor a realidade da profissão de professor no Brasil, foi utilizado um levantamento inédito da área da Educação: durante mais de três meses (de dezembro de 2006 a março de 2007), a Nova Escola procurou as vinte e seis secretarias estaduais (mais a do Distrito Federal) e as 26 secretarias municipais das capitais. A todas foi solicitado completar uma lista com vinte e cinco itens que consistiam

[...] do total de escolas, alunos e professores na Educação Infantil e no Ensino Fundamental aos critérios de promoção na carreira, passando pelo piso salarial, a porcentagem de concursados e os principais benefícios, como bônus, capacitações e descontos em eventos culturais. (GUIMARÃES; FARIA, 2007, p. 28).

O texto informa que o resultado é uma profissão desigual, com cobranças e recompensas também desiguais e isso se justifica pelo fato das regras para o exercício do Magistério serem definidas pelas Câmaras Municipais, pelas Assembleias Legislativas e pelos Executivos locais.

Outra grande disparidade foi encontrada com relação aos salários, que são baixos, o que, segundo o texto, dá força ao movimento para a criação de um piso salarial nacional.

Também em 2007 (MENEZES, 2007c, p. 26), a revista abordou a questão da desigualdade, afirmando que

A profissão de professoras e professores, sua formação e sua condição de trabalho, deveriam ser estratégicas, se quisermos romper esse ciclo de desigualdade crescente: quem tem melhor condição social obtém Educação com mais qualidade e quem recebe essa Educação boa avança socialmente. (MENEZES, 2007c, p. 26).

Os cursos de Pedagogia e as licenciaturas, por causa do desprestígio e da expectativa de baixa remuneração, estão entre os menos disputados. Portanto, é necessário bolsas de estudos para os professores durante a sua formação e também uma nova lógica de reconhecimento do trabalho docente "[...] premiando e promovendo os responsáveis pela evolução dos que mais precisam da escola” (MENEZES, 2007c, p. 26). 
Ainda em 2007 a revista publicou um artigo a respeito de uma pesquisa realizada pela Nova Escola e pelo Ibope, com o objetivo principal de investigar como os professores brasileiros se relacionam com o trabalho, os alunos e a escola e de que forma eles enxergam o futuro da profissão (A EDUCAÇÃO, 2007), concluíram que os professores amam a profissão, mas apenas $21 \%$ estão satisfeitos com ela. Um grupo de educadores foi convidado para debater os resultados: Celso Favaretto, Lino de Macedo, Luís Carlos de Menezes, Maria Cristina Mantovanini, Sônia Kruppa, Telma Weisz e Vera Trevisan. Finalizando o texto está o objetivo do artigo: "Com a divulgação (e análise) desses números, NOVA ESCOLA acredita estar contribuindo para uma reflexão coletiva que aponte caminhos para melhorar ainda mais a Educação, em especial na rede pública de nosso país" (A EDUCAÇÃO, 2007).

Também em maio de 2007 foi publicada uma entrevista realizada com o então ministro da Educação Fernando Haddad (GROSSI; GENTILE, 2007, p. 20-24). Na entrevista o ministro informa que o Brasil já tinha um Plano, referindo-se ao Plano de Desenvolvimento da Educação (PDE) e que este plano é o primeiro a levar em conta a questão da qualidade, além de defender a valorização dos professores (mais formação e melhores salários) como única forma de garantir um ensino decente para todos. Dentre as metas definidas pelo Ministério da Educação (MEC) encontramos: da criação do piso salarial para o magistério a grandes investimentos em formação (parceria da Universidade Aberta do Brasil com instituições de Ensino Superior). O ministro ressaltou : "O que realmente importa é fazer valer as leis que já existem e valorizar a profissão docente" (GROSSI; GENTILE, 2007, p. 20). Além disso, Haddad ainda afirmou que a educação brasileira precisa melhorar em três dimensões, que são salário, formação e recuperação da figura docente. Para resgatar a imagem docente o ministro informou que pretendia enaltecer a profissão veiculando pequenos programas de rádio e TV, mostrando que os professores são profissionais dedicados e necessários para vencermos a guerra contra o ensino de má qualidade.

Em novembro de 2007 a revista, destacou o Prêmio Professor Nota Dez, da Fundação Victor Civita, já na sua décima edição e que teve mais de 3,3 mil trabalhos inscritos (SEMPRE, 2007).

Em 2008 a revista publicou que “[...] A aprovação do piso para os professores trouxe o debate sobre a importância da Educação para o âmbito nacional" (EDUCAÇÃO, 2008). Fernando Haddad, então Ministro da Educação, afirma que a 
aprovação do piso nacional é o primeiro passo de um processo de revalorização dos professores.

No mesmo ano a revista publicou um artigo mostrando que os países que contam com os melhores sistemas educacionais utilizam a valorização da profissão docente como chave para garantir a qualidade e o artigo afirma que esses países podem inspirar a busca por soluções (MARTINS; SANTOMAURO; RATIER, 2008, p. 58 61). O artigo foi produzido com base em um estudo da consultoria americana McKinsey intitulado Como os Sistemas Escolares de Melhor Desempenho do Mundo Chegaram ao Topo, as descobertas do estudo foram sintetizadas em quatro lições: "selecionar os melhores professores, cuidar da formação docente, não deixar nenhum aluno para trás e capacitar equipes gestoras" (MARTINS; SANTOMAURO; RATIER, 2008, p. 58). Ressaltou-se também que os sistemas de sucesso estimulam continuamente a formação docente completa e de qualidade, inicial ou continuada.

Em 2009 a revista publicou informações a respeito de um estudo intitulado A Formação Inicial e a Iniciação Profissional do Professor a as Implicações sobre a Qualidade do Ensino, realizada pela Fundação SM e pela Organização dos Estados Ibero-Americanos (SANTOMAURO, 2009a, p. 34). Pela pesquisa, constatou-se que $71 \%$ dos entrevistados se lembram dos primeiros anos de carreira com satisfação, porém, $40 \%$ dos iniciantes consideram difícil ensinar e 39\% pensaram em abandonar a docência nesses anos.

No ano seguinte (2010) um artigo (SALLA; RATIER, 2010, p. 68-69) já informava que um estudo encomendado pela Fundação Victor Civita (FVC) à Fundação Carlos Chagas (FCC) apontou que, dentre os apenas 2\% dos 1501 estudantes do Ensino Médio ouvidos pretendem graduar-se em Pedagogia ou alguma outra licenciatura como primeira opção no vestibular, o que mostra a baixa atratividade da carreira docente. A profissão tende a ser procurada por jovens da rede pública de ensino, muitos de nichos sociais menos favorecidos.

No mesmo ano, a revista publicou um artigo buscando apontar saídas para a crise da atratividade da carreira docente (PAGANOTTI, 2010, p. 70-71). A Fundação Victor Civita (FVC) e a Fundação Carlos Chagas (FCC) reuniram dezessete especialistas que apontaram as seguintes sugestões: oferecer salários iniciais mais altos, propor bons planos de carreira, melhorar as condições de trabalho, focar a formação em serviço nas dificuldades em sala, oferecer uma boa experiência escolar, melhorar a 
formação inicial, resgatar o valor do professor na sociedade e tratar o professor como profissional.

Um outro artigo aborda, ainda em 2010, a questão dos docentes substitutos (MARTINS; TAKADA, 2010, p. 90-93), que são profissionais com um vínculo com tempo determinado com as redes, raramente superior a um ano. $\mathrm{O}$ texto alerta para a necessidade de profissionais que cubram licenças e outras situações, para evitar aulasvagas, então, é necessário cuidar da formação deles, integrá-los à escola e repensar a situação contratual dos mesmos.

Também em 2010, outro artigo informou que o prazo para que os municípios elaborassem seus planos de carreira para o Magistério já se esgotou em julho (RATIER, 2010, p. 22), porém, muitas cidades ainda se encontram sem regulamentação.

\section{Práticas de sala de aula}

A revista escola, no período da nossa pesquisa, publicou cinco artigos, dentre os selecionados no âmbito do COPPE, que tratam de assuntos diretamente voltados para a sala de aula.

O primeiro artigo que abordamos aqui diz que ensinar bem é prender a atenção da turma e que, para tanto, o docente pode tirar proveito da voz, dos gestos e também da postura para despertar nos alunos a vontade de participar (ENSINAR, 2004, p. 20), em outras palavras, “[...] não basta um discurso bem articulado para ter a atenção da classe. É preciso mais: é preciso seduzir!" (ENSINAR, 2004, p. 20). O texto sugere até a utilização de técnicas de teatro. Outra dica é compreender que atos de indisciplina não são agressões pessoais, mas sim comportamentos naturais de crianças e adolescentes.

Na mesma edição do mês de março de 2004 foi publicada uma entrevista realizada com Inés Aguerrondo (FERRARI, 2004, p. 22-24), naquela época responsável pela unidade de formação do Instituto Internacional de Planejamento da Educação da Organização das Nações Unidas para a Educação, a Ciência e a Cultura (Unesco) em Buenos Aires, conduzindo estudos sobre capacitação docente uruguaia e argentina. Inés afirma que é necessário transformar a concepção de escola, pois nos falta o sentimento de que o docente trabalha para o bem comum, para melhorar a aprendizagem, para construir uma cultura (FERRARI, 2004, p. 23). Além disso, para ela as competências fundamentais que o professor das séries iniciais deve ter são: “[...] conhecer em 
profundidade os conteúdos a serem ensinados, o processo de aprendizagem e as possibilidades para tudo isso funcionar" (FERRARI, 2004, p. 24).

Ainda em 2004, a revista se apresentou em um artigo como canal de comunicação entre professores (REVISTA, 2004, p. 12), isso se explica pela utilização da seção Quadro de Avisos, utilizada por interlocutores dispostos a trocar experiências na área da educação. $\mathrm{O}$ artigo relata que, a partir do contato de professores, foi possível até aos alunos trocarem correspondências com colegas de outros lugares.

Em 2008 um artigo apresenta dados da pesquisa intitulada A Qualidade da Educação sob o Olhar dos Professores, realizada pela Fundação SM e pela Organização dos Estados Ibero-Americanos, com professores da Educação Básica de 19 estados (VICHESSI, 2008, p. 39-40). Os resultados apontam que há falta de conexão entre ensino e aprendizagem na Educação brasileira.

A revista abordou em artigo de 2010 o novo perfil do professor, tendo em vista que os alunos de hoje são diferentes dos alunos de décadas atrás, informando no texto que o Governo Federal está criando o Exame Nacional de Ingresso na Carreira Docente, para estabelecer parâmetros de qualidade na hora de escolher quem vai lecionar para as crianças da Educação Infantil e do Ensino fundamental em todo o país (MARTINS; MOÇO, 2010, p. 47-53). São características desse novo perfil docente: ter boa formação, usar as novas tecnologias, atualizar-se nas novas didáticas, trabalhar bem em equipe, planejar e avaliar sempre e ter atitude e postura profissionais.

\section{Considerações finais}

Após a leitura dos textos selecionados foi possível perceber como a revista Nova Escola se posiciona a respeito de cada uma das categorias que elencamos no tema formação de professores. Para reforçar seu ponto de vista, a revista utiliza opiniões, exemplos e práticas de docentes da educação pública de todo o país, enquanto também apresenta opiniões de teóricos da educação e até mesmo do Ministro da Educação.

Quanto à formação inicial, constatamos que a revista não é favorável à formação inicial apenas em cursos superiores, critica a amplitude da formação pretendida pelos cursos de Pedagogia, e, ao mesmo tempo, também critica o pouco espaço dos conteúdos da Educação Básica e aos aspectos didáticos do trabalho docente nesses cursos. Além 
disso, defende que a formação do magistério deve ser feita em regime de colaboração entre União, estados e municípios, pelas instituições de ensino superior públicas.

Quanto à formação continuada, a revista valoriza a formação em grupos de professores, para a reflexão em serviço, principalmente dentro da própria escola. A RNE também aponta que muito se perde tentando superar a má formação inicial, enquanto as atividades deveriam ser para além dessa formação e ainda defende que há verbas para a formação continuada acontecer efetivamente no país.

Quanto à carreira, considerando-se que o magistério apresentava-se no período em estudo (2003 a 2010) como profissão desigual, com cobranças e recompensas também desiguais nos diferentes estados do país (devido ao fato das regras para o exercício do Magistério serem definidas pelas Câmaras Municipais, pelas Assembléias Legislativas e pelos Executivos locais, segundo os artigos), percebe-se nos textos que a revista defende a aprovação do piso salarial nacional.

A revista defende também a revalorização dos professores, inclusive por campanhas enaltecendo a profissão, campanhas nacionais e, especificamente, o Prêmio Professor Nota Dez, da Fundação Victor Civita. A valorização dos docentes (melhor formação e melhores salários) também aparece por meio do PDE.

Ainda para incentivar a carreira, percebemos que a revista defende a oferta de salários iniciais mais altos, a proposta de bons planos de carreira, melhoria das condições de trabalho, voltar a formação em serviço para as dificuldades encontradas cotidianamente em sala de aula, oferecer uma boa experiência escolar, melhorar a formação inicial, resgatar o valor do professor na sociedade e tratar o professor como profissional.

Enfim, quanto às práticas de sala de aula, a revista defende que é necessário prender a atenção da turma; não ver a indisciplina como ofensa, mas sim como comportamento natural; reconhecer que o docente trabalha para o bem comum; conhecer em profundidade os conteúdos a serem ensinados e, assim, conectar o ensino à aprendizagem. Para tanto, faz-se necessário um novo perfil docente: ter boa formação, usar as novas tecnologias, atualizar-se nas novas didáticas, trabalhar bem em equipe, planejar e avaliar sempre e ter atitude e postura profissionais.

Diante de todo esse quadro por nós exposto acreditamos que é possível afirmar que, para além de suas opiniões, a Revista Nova Escola (RNE) também colabora com a formação continuada dos professores, se entendermos que a divulgação dos mais diferentes conteúdos curriculares, bem como o debate dos temas da educação, presentes 
com maior força em cada momento histórico, fazem parte da formação continuada (no sentido de por toda a vida) dos professores.

\section{Referências}

A EDUCAÇÃO vista pelos olhos do professor. Nova Escola. São Paulo, nov. 2007. p. 1-9. Disponível em: http://revistaescola.abril.com.br. Acesso em: 18/março/2014.

DIDONÊ, Débora. Por uma formação inicial com mais qualidade. Nova Escola. São Paulo, ago. 2007. p. 60-64.

DURHAM, Eunice R. Os limites do curso de Pedagogia. Nova Escola. São Paulo, jun./jul. 2006. p. 78.

EDUCAÇÃO na pauta. Nova Escola. São Paulo, set. 2008. Disponível em: http://revistaescola.abril.com.br. Acesso em 18/março/2014.

ENSINAR bem é... prender a atenção da turma. Nova Escola. São Paulo, mar. 2004. p.20.

ESTUDO em 23 países revela o cenário da formação continuada. Nova Escola. São Paulo, set. 2009. p. 50.

FERRARI, Márcio; FUSCO, Karina. O curso de Magistério vai acabar? Nova Escola. São Paulo, maio 2004. p. 32-34.

FERRARI, Márcio. Eu acredito no sucesso da Educação - entrevista com Inés Aguerrondo. Nova Escola. São Paulo, mar. 2004. p. 22-24.

FERRARI, Márcio. A democratização do ensino exige nova linguagem em classe entrevista com Philippe Perrenoud. Nova Escola. São Paulo, nov. 2004. p. 20-22.

GROSSI, Gabriel Pillar; GENTILE, Paola. O país precisa acordar para a importância da Educação - entrevista com Fernando Haddad. Nova Escola. São Paulo, maio 2007. p. 20-24.

GURGEL, Thais. A origem do sucesso (e do fracasso escolar). Nova Escola. São Paulo, out. 2008a. p. 48 - 49.

GURGEL, Thais. Ao mesmo tempo, tão perto e tão longe. Nova Escola. São Paulo, out. 2008b. p. 50 - 53.

GUIMARÃES, Arthur. Capacitação que funciona. Nova Escola. São Paulo, nº 160, vol. 18, mar. 2003. p. 60-62.

GUIMARÃES, Arthur; FARIA, Fabiana. Uma profissão, várias realidades. Nova Escola. São Paulo, nº 201, abr. 2007. p. 26-37. 
LEVORATTI, Liliana. Descompasso de objetivos. Nova Escola. São Paulo, nov. 2008. p. 76-79.

MARTINS, Ana Rita et al. Não basta (só) tapar os buracos. Nova Escola. São Paulo, out. 2008. p. $54-57$.

MARTINS, Ana Rita; MOÇO, Anderson. O novo perfil do professor. Nova Escola. São Paulo, out. 2010. p. 47-53.

MARTINS, Ana Rita; TAKADA, Paula. Banco de reservas. Nova Escola. São Paulo, ago. 2010. p. 90-93.

MARTINS, Ana Rita; SANTOMAURO, Beatriz; RATIER, Rodrigo. Eles podem inspirar a busca por soluções. Nova Escola. São Paulo, out. 2008. p. 58 - 61.

MENEZES, Luis Carlos de. Seis etapas em direção a uma escola de qualidade. Nova Escola. São Paulo, out. 2007b. p. 22.

MENEZES, Luis Carlos de. Só o bom professor salva. Nova Escola. São Paulo, maio. 2007a. p. 18.

MENEZES, Luis Carlos de. O ciclo da desigualdade. Nova Escola. São Paulo, set. 2007c. p. 26.

MENEZES, Luis Carlos de. Chegou, enfim, a vez dos professores. Nova Escola. São Paulo, abr. 2008. p. 122.

NICOLIELO, Bruna. Número de não formados diminui. Nova Escola. São Paulo, jun./jul. 2010. p. 56.

PAGANOTTI, Ivan. Buscar os melhores. Nova Escola. São Paulo, jan./fev. 2010. p. 70-71.

PELLEGRINI, Denise; GROSSI, Gabriel Pillar. A formação docente é prioridade para o Ministério - entrevista com Fernando Haddad. Nova Escola. São Paulo, out. 2008. p. 32-36.

PRADO, Ricardo. Aprender sempre. Nova Escola. São Paulo, nº 161, vol. 18, abr. 2003. p. 18.

RATIER, Rodrigo. Legislação - Planos pela metade. Nova Escola. São Paulo, nov. 2010. p. 22.

REVISTA Escola é canal de comunicação entre professores. Nova Escola. São Paulo, dez. 2004. p. 12.

SALLA, Fernanda; RATIER, Rodrigo. Escolha de poucos. Nova Escola. São Paulo, jan./fev. 2010. p. 68-69. 
SANTOMAURO, Beatriz. Formação - Início de carreira docente é sempre marcante. Nova Escola. São Paulo, dez. 2009a. p. 34.

SANTOMAURO, Beatriz. Especialistas fora de lugar. Nova Escola. São Paulo, ago. 2009. p. 46.

SEMPRE do lado do professor. Nova Escola. São Paulo, nov. 2007. p. 6.

VEM aí a Rede Nacional de Formação de Professores. Nova Escola. São Paulo, nº 178, dez. 2004.

VICHESSI, Beatriz. Poucos cursos de Pedagogia são excelentes. Nova Escola. São Paulo, out. 2009. p. 44.

VICHESSI, Beatriz. Dá pra ensinar se ninguém aprende? Nova Escola. São Paulo, out. 2008. p. 39-40.

\section{Como referenciar este artigo}

LABEGALINI, Andréia Cristina Fregate Baraldi; BRANDÃO, Carlos da Fonseca. A Revista Nova Escola no período de 2003 a 2010 e a formação de professores. Revista on line de Política e Gestão Educacional, Araraquara, v.20, n.03, p. 710-728, 2016. Disponível em: <http://dx.doi.org/10.22633/rpge.v20.n3.9765>. ISSN: 1519-9029.

Submetido em: julho/2016

Aprovado em: setembro/2016 